\title{
Mechanized Placement of Drip Tape in Potato Comb
}

\author{
Boris M. Kizyaev ${ }^{1}$, Victor I. Balabanov², and Natalia B. Martynova ${ }^{2, *}$ \\ ${ }^{1}$ All-Russian Research Institute of Hydraulic Engineering and Land Reclamation named after A.N. \\ Kostyakov, 127550, Moscow, Russian Federation \\ ${ }^{2}$ Russian State Agricultural University - MSHA named after K.A. Timiryazev, 127550, Moscow, \\ Russian Federation
}

\begin{abstract}
Over the past two years, decrease in potato yield has been observed in the Moscow region. One of the main reasons is unfavorable weather conditions. To obtain a guaranteed yield, as well as to improve the quality of products, it is necessary to carry out reclamation works, including additional irrigation. Creation of the optimal water - air balance of the plant throughout the entire growing season will increase productivity, and improve the quality of agricultural products. Drip irrigation is the most economical method of irrigation, but its widespread use is hindered by the high proportion of manual labor when installing the drip tape. A mechanized method of laying the drip tape by placing the working equipment on the Grimme GF-75/4 comb former is offered. The existing methods for determining the irrigation rate do not consider the parameters of the humidification circuit, which leads to excessive irrigation and additional losses of irrigation water. The paper offers a method for determining the irrigation rate considering the shape of the humidification circuit and its geometric parameters.
\end{abstract}

\section{Introduction}

In the Moscow region, after the record potato harvest in 2019, which amounted to 460 tons, there has been a decline [1]. Last year, the region received less than due 36 tons of the planned harvest, and this year there are reasons to believe that the situation will repeat itself $[2,3]$. The quality of the products has also noticeably decreased. For consumers, potatoes with a diameter of over $55 \mathrm{~mm}$ are most in demand, and until last year the share of such products intended for food purposes was about $80 \%$ [4, 5]. Last year, this figure dropped to $50 \%$, and economy class chain stores were forced to make concessions, the rest switched to imports. This year, the region will also not receive part of the planned harvest, and imported products may appear on store shelves in the fall, and not in the spring, as in previous years.

Until 2020, there was a steady growth in this industry segment, the indicators improved due to the return of land to agricultural use during cultural and technical reclamation within

\footnotetext{
* Corresponding author: nmartinova@rgau-msha.ru
} 
implementation of Agriculture of the Moscow Region State Program (Development of Reclamation of Agricultural Land subprogram) adopted in 2014 (Figure 1).

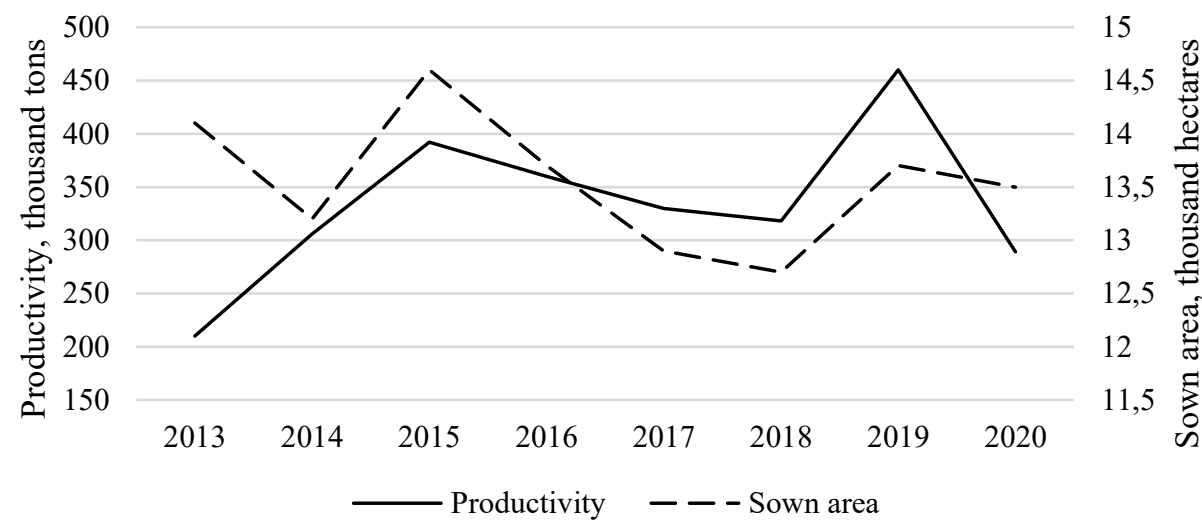

Fig. 1. Commissioning new areas and dynamics of potato yield.

Therefore, fluctuations in yield were compensated by introduction of new territories into agricultural circulation [6,7]. Last year, implementation of the program was completed, and the last two years there has been a drop in yield, the main reason is the climatic features of recent years. In 2020, due to heavy rains at the beginning of summer, a significant part of the crop perished, while the harvested crop was significantly inferior to the indicators of previous years in terms of quality indicators [8]. In 2021, the negative trend worsened. This time, the reason was the almost complete absence of precipitation in the middle of summer, during the period when the daily water consumption of potatoes reaches its maximum values $[9,10]$. The climatic feature of the Moscow region is fluctuations in precipitation within wide limits both during the growing season and throughout the year: high-water years alternate with moisture-deficient years (Figure 2).

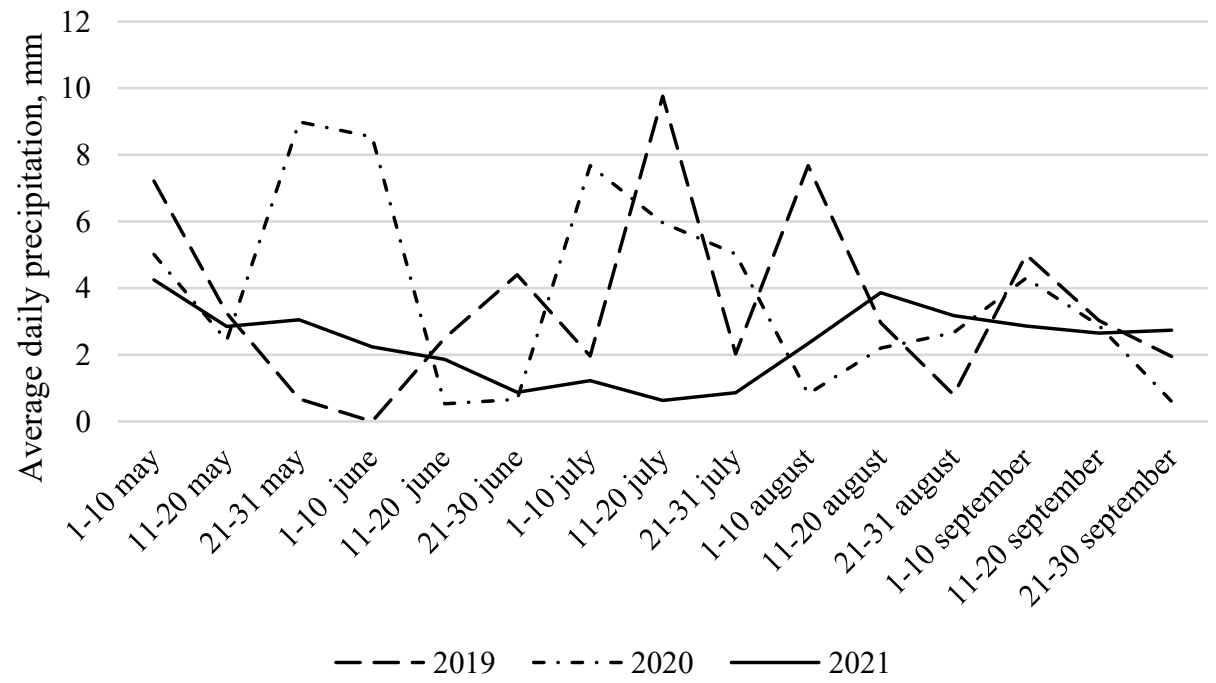

Fig. 2. The dynamics of precipitation within the growing season. 
In such conditions, obtaining the stable harvest becomes a difficult task. The region, which ranks the 3rd in the Central Region in terms of gross harvest of potatoes, shall minimize weather risks. For the region with a widely developed network of processing enterprises with a total capacity of 170 thousand tons, obtaining a guaranteed yield that meets world quality standards is a task that requires an immediate solution.

Conducting the agro-reclamation measures will allow maintaining the optimal regime of water consumption throughout the entire growing season of plants. This will not only increase yields, but also improve the quality of combs. The total area of ameliorated land in the region is 395.7 thousand hectares, but most of it is in an unsatisfactory condition [11]. When carrying out irrigation measures, surface watering and sprinkling are used. More than half of the used sprinkler machines are beyond their service life, and new arrival - over $90 \%$ are imported equipment. This runs counter to the import substitution program and the concept of the development of agricultural science developed by the distancing of agricultural sciences of the Russian Academy of Sciences that was supposed to increase the yield of crop production by $117 \%$ compared to 2017 by introducing promising domestic machines into agriculture [12]. At present, the vast majority of promising domestic machine designs are at the stage of designing and testing prototypes. It is doubtful that by the specified date the basis of the park of sprinklers will be made up of mass-produced domestic equipment.

The way out of this situation could be an increase in the area occupied by drip irrigation. So far, this method of irrigation has not found widespread use in the region, its share is several percent. However, the advantages of this irrigation method are obvious: the delivery of moisture directly to the root zone makes it possible to almost completely eliminate the loss of water for evaporation and filtration into deep soil layers. For drip irrigation, the uneven terrain is not a problem, the complex configuration of the fields, in the spaces between rows, since they remain not watered, the growth of weeds is inhibited. Domestic enterprises are increasing the output of drip tape: in 2020, the output of the Russian - Israeli enterprise Polyplastic Rivulis Irrigation Pipeline Systems (St. Volzhsky, Volgograd Region) amounted to 200 million linear meters per year, New Age of Agrotechnology (St. Chaplygin, Lipetsk region) - 270 million linear meters per year. This made it possible to reduce the import of drip tape from $60 \%$ to $30-40 \%$, but did not lead to a noticeable increase in the areas occupied by drip irrigation [13].

One of the reasons is the low degree of mechanization of the drip tape installation. The American companies Andros and Rain flo specialize in production of specialized equipment for laying drip tape. However, in their line of models there is no specialized machine for placing drip tape in a potato comb. Use of machines that are not intended for this type of work leads to uneven tension of the drip tape within installation process and, as a consequence, its twisting or breakage [14]. Creation of a special stacker of drip tape in a potato comb will expand application of this irrigation method.

\section{Materials and Methods}

When designing the working equipment of the drip tape stacker, the resistances arising during the laying process were determined [15]:

$$
\begin{gathered}
F_{s}=R_{e}+F_{p t}=R_{e}+F_{f t}+F_{i c}+F_{f c}= \\
=\mu \cdot G_{s}+k_{p} \cdot h \cdot b+\varepsilon \cdot h \cdot b \cdot v^{2}+\left(f_{a} \cdot G_{c} \cdot d_{a} \cdot d_{c}^{-1}+2 \cdot G_{c} \cdot l_{c} \cdot d_{c}^{-1}\right) \cdot\left(1+\mathrm{e}^{f_{a} \cdot \alpha}\right)
\end{gathered}
$$

where: $F_{\mathrm{pt}}$ - resistance from pulling the tape, $\mathrm{kN} ; F_{\mathrm{ft}}$ - friction resistance of the tape in the stacker, $\mathrm{kN} ; F_{\mathrm{ic}}$ - force from unbalance of the coil, $\mathrm{kN} ; F_{\mathrm{fc}}$ - resistance to friction of 
the coil on the surface of the axis, $\mathrm{kN} ; R_{\mathrm{e}}$ - soil resistance to digging, $\mathrm{kN} ; f_{a}$ - coefficient of friction of the axle in the bearings; $G_{c}$ - weight of the tape coil, $\mathrm{kN} ; d_{a}$ - axis diameter, $\mathrm{m} ; d_{c}$ - coil diameter, $\mathrm{m} ; l_{c}$ - displacement of the center of gravity of the coil from the axis of rotation, $\mathrm{m} ; \alpha-$ tape wrap angle; $\mu$ - coefficient of friction of the working body on the ground; $G_{s}-$ stacker weight, $\mathrm{kN} ; k_{p}-$ specific resistance to cutting, $\mathrm{kN} / \mathrm{m}^{2} ; \varepsilon-$ coefficient that takes into account the effect of cutting speed on the resistance to digging; $h$ - development depth, $\mathrm{m} ; b$ - working width, $\mathrm{m}, v$ - stacker speed, $\mathrm{m} / \mathrm{s}$.

When designing a drip humidification system, the irrigation rate shall be determined. The existing calculation methods do not take into account the shape of the humidification circuit, this leads to inaccurate results, mainly to excessive watering [16]. In the process of irrigation, water is delivered to the soil in small portions at regular intervals. The humidification circuit has a semi-elliptical shape [17]. Since gravitational and capillary forces act on a drop in the soil, the speed of moisture propagation in the horizontal and vertical directions is not the same. The vertical boundary of the circuit shall be determined [18]:

$$
\mathrm{z}=2 \mathrm{~A}^{-0,5} \sqrt{D_{0} \cdot e^{\beta\left(W_{m}-W_{0}\right) \cdot \mathrm{t}}}
$$

where: $\mathrm{A}$ - correction factor; $\mathrm{W}_{\mathrm{m}}$ - relative soil moisture; $\mathrm{W}_{0}$ - initial soil moisture; $\mathrm{t}$ time, $s ; \beta-$ parameter depending on soil and moisture content; $\mathrm{D}_{0}-$ diffusivity coefficient at initial moisture content $\mathrm{W}_{0}$.

The coefficients given in the formula can be determined by the formula [19]:

$$
\beta=\frac{1}{w_{1}-W_{0}} \ln \left(\frac{3\left(W_{1}-W_{m}\right)^{3,5}}{w_{1}^{2}\left(W_{0}-W_{m}\right)^{3,5}\left(\frac{1}{w_{0}^{2}}+2 \frac{W_{0}}{w_{1}^{3}}\right)}\right)
$$

The diffusion coefficient shall be determined from the expression:

$$
\mathrm{D}_{0}=\frac{\mathrm{K}_{\mathrm{F}} \Psi_{m} W_{m}}{1-\left(\frac{W_{m}}{\mathrm{~W}_{1}}\right)^{3}}\left(\frac{\mathrm{W}_{0}-W_{m}}{\mathrm{~W}_{1}-W_{m}}\right)^{3,5} \cdot\left(\frac{1}{\mathrm{~W}_{0}^{2}}+2 \frac{\mathrm{W}_{0}}{\mathrm{~W}_{1}^{3}}\right)
$$

where: $\Psi_{\mathrm{m}}$ — value of soil moisture pressure at moisture $\mathrm{W}_{\mathrm{m}} ; \mathrm{W}_{1}$ - the limiting field moisture capacity of the soil; $\mathrm{K}_{\mathrm{F}}$ - filtration coefficient.

To determine the horizontal boundary of the circuit, use the formula [20]:

$$
x=\sqrt{\frac{2 t D_{0} e^{\beta\left(W-W_{0}\right) \cdot \sqrt{A}}}{\sqrt{A}-\beta\left(W_{m}-W_{0}\right) \sqrt{2 D_{0} e^{\beta\left(W_{m}-W_{0}\right)}}}}
$$

Knowing the coordinates of the humidification circuit, the irrigation rate shall be determined as follows:

$$
m=\frac{2 \cdot 10^{-2} \pi z x^{2}\left(W_{1}-W_{0}\right)}{3 \cdot l_{d} \cdot \mathbf{b}_{d}}
$$

where: $1_{d}$ - distance between droppers, $m ; b_{d}$ - distance between adjacent combs, $m$.

Calculation of the irrigation rate considering the parameters of the humidification circuit will allow avoiding excessive irrigation and rational use of irrigation water. 


\section{Results and Discussion}

Laboratory studies have confirmed that the traction resistance arising during the laying of the tape does not exceed $180 \mathrm{~N}$ at an estimated laying depth of $20-80 \mathrm{~mm}$ (Figure 3).

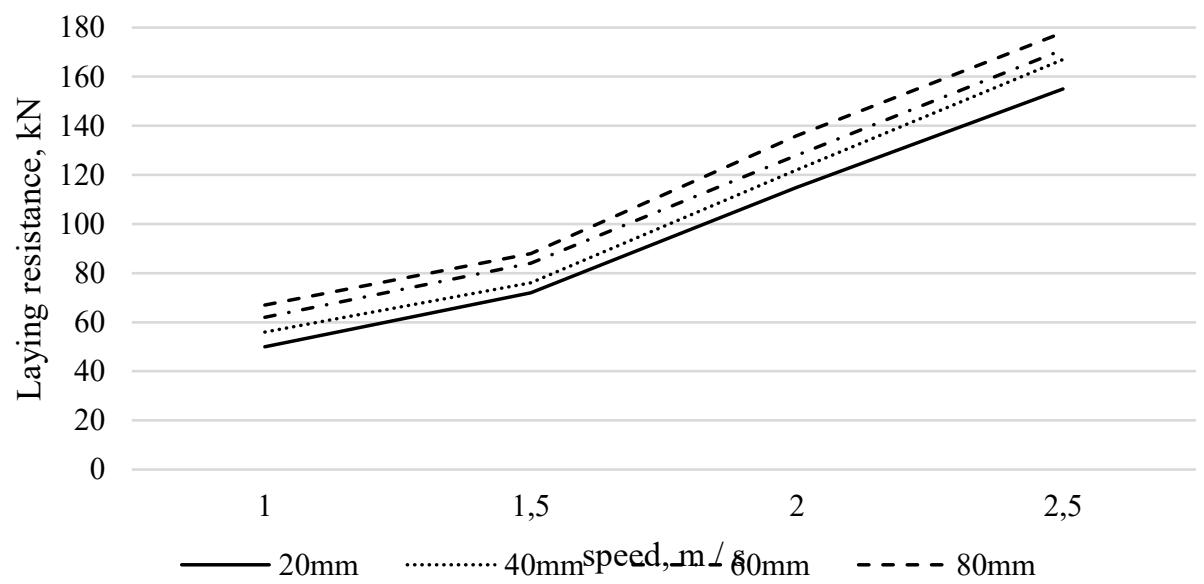

Fig. 3. Resistance to drip tape stacking.

Therefore, it is rational to place the working equipment of the tape stacker on the comb former, combining the process of forming the comb with the laying the drip tape. This will reduce energy costs and increase productivity. The working equipment of the drip tape stacker was installed on the Grimme GF-75/4 comb former and the drip tape was laid on the experimental site of the Field Experimental Station of the Russian State Agricultural University named after K.A. Timiryazev (Figure 4).

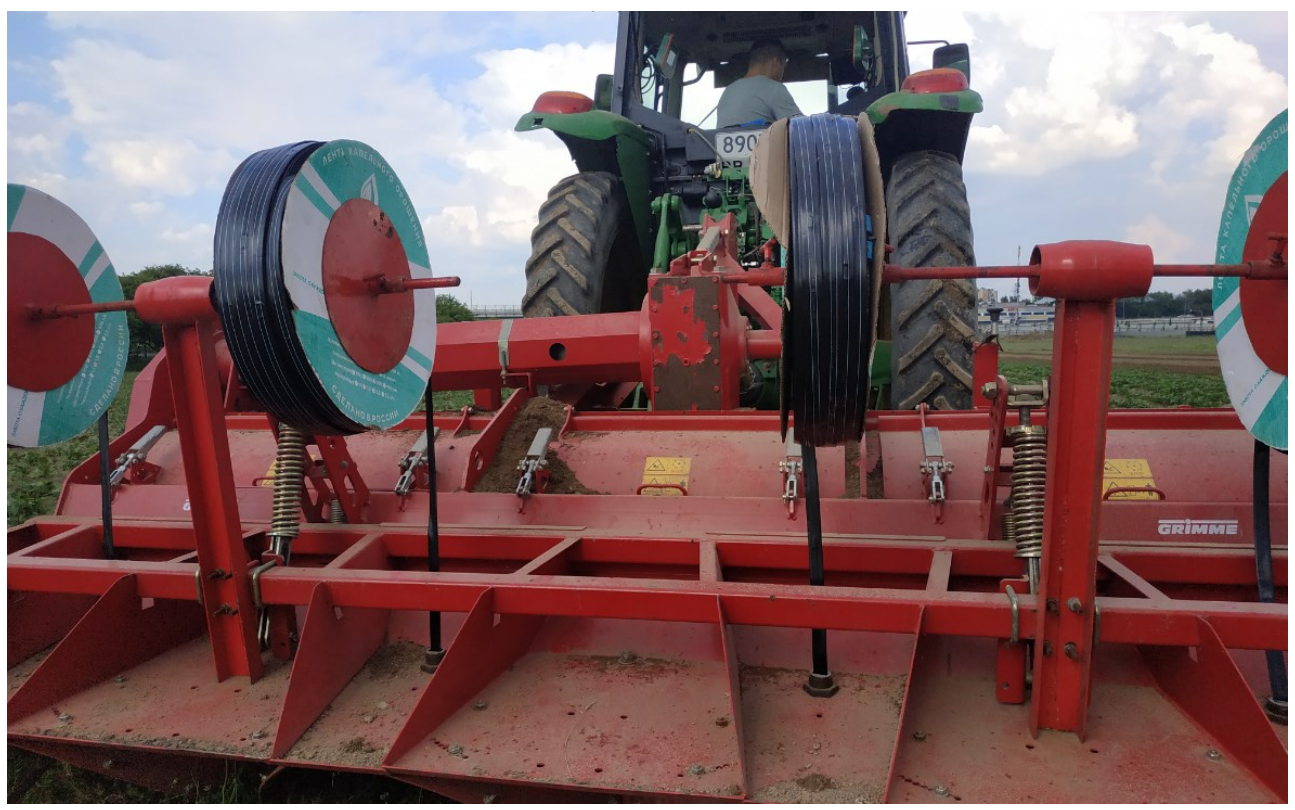

Fig. 4. Tests of the drip tape stacker. 
In the process of further study, the boundaries of the humidification circuit within irrigation were determined, the irrigation rate was calculated and a drip tape with optimal parameters for a given crop was selected (Figure 5).

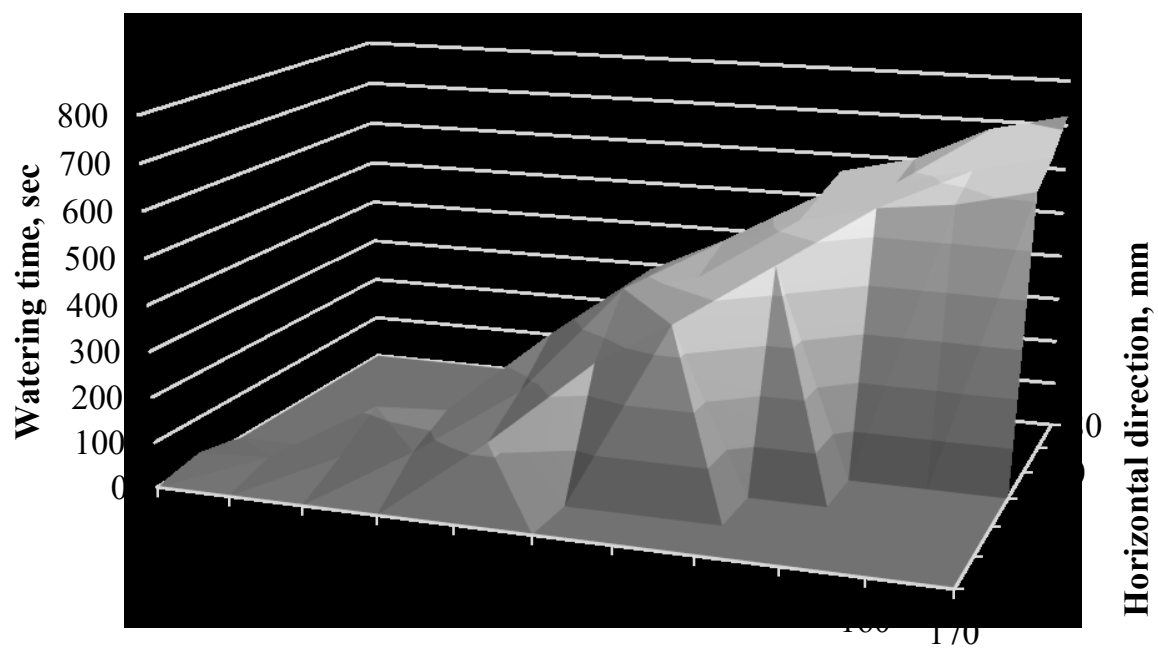

Vertical direction, $\mathbf{m m}$

Fig. 5. The rate of the humidification circuit formation.

Watering was carried out using the calculated irrigation rate when the pre-irrigation moisture content reached $70 \%$ of the maximum field moisture capacity. Considering the weather conditions, the time between waterings was adjusted (Figure 6).

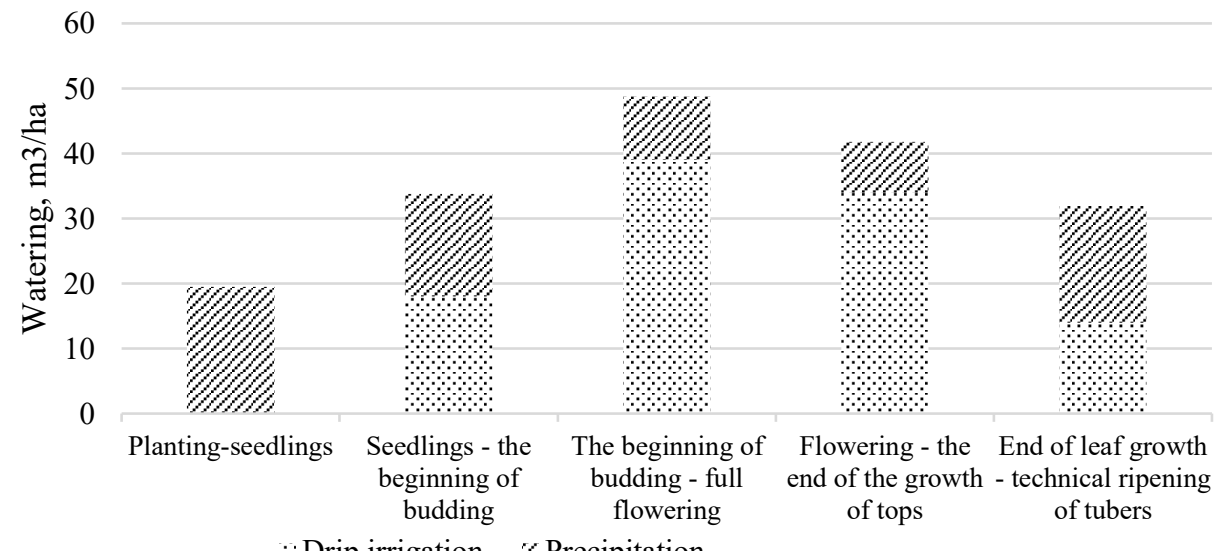

Fig. 6. Dynamics of daily water consumption.

\section{Conclusion}

In the Moscow region, in order to obtain a guaranteed potato crop, it is necessary to use agromeliorative measures. The advantage of drip irrigation is the ability to deliver irrigation water directly to the root-inhabited space, which practically eliminates the loss of water for 
evaporation and filtration into deep soil layers. Creation of the specialized machine for placing drip tape in the potato comb will expand the application of this irrigation method. Use of the drip tape stacker based on the Grimme GF-75/4 comb former made it possible to reduce labor costs by $22-28 \%$, and the combination of technological operations for forming potato combs and laying the drip tape - to increase work productivity by 32 $36 \%$ and reduce energy costs by $16 \%$. Calculation of the irrigation rate considering the parameters of the humidification circuit made it possible to reduce the irrigation water consumption by $12 \%$.

\section{Acknowledgements}

The article was prepared with the support of the Ministry of Education and Science of Russia within the framework of Agreement No. 075-15-2021-032 dated March 23, 2021 on provision of a grant in the form of a subsidy for creation and development of an engineering center on the basis of an educational institution of higher education and (or) a scientific organization within the framework of the federal project Development of Infrastructure for Research and Training of the national project Science and Universities.

\section{References}

1. A.S. Apatenko, Bulletin of the Federal State Educational Institution of Higher Professional Education "Moscow State Agroengineering University named after V. P. Goryachkin", 2(58), 23 (2013)

2. N.S. Sevrugina, A.S. Apatenko, E.V. Voytovich, Environmental management, 2, 115 (2020)

3. V.A. Shevchenko, G.I. Bondareva., A.M. Solovjov, L.V. Kudrjavtzeva, Engineering for rural Development, 1065 (2020)

4. L.V. Kireycheva., L.A. Lentyaeva Influence of agricultural Production on Pollution of water Bodies. Environmental management, 5, 18 (2020)

5. V.A. Shevchenko, V.A. Gubin V.K., L.V.Kudrjavtzeva, The Herald of the Moscow State Agricultural Engineering University named after V.P. Goryachkin, 88, 27 (2018)

6. N.N. Dubenok, D.A.Bolotin, S.D Fomin., A.G. Bolotin, News of the Nizhnevolzhsky agro-university complex: science and higher professional education., 4, 22 (2017)

7. V.N. Krasnoshchekov, D.G. Olgarenko, Prirodoobustroystvo, 4, 51 (2016)

8. M.N.Makani, S.A. Sargent, L. Zotarelli D.J. Huber, C.A. Sims, Scientia Horticulturae., 197, 428 (2015)

9. V.V. Borodychev, M.N. Lytov, A.S. Ovchinnikov A.S., V.S. Bocharnikov, Bulletin of the Nizhnevolzhsky agro-university complex: science and higher professional education., 4(40), 21 (2015)

10. J. Reyes-Cabrera, L. Zotarelli, D.L. Rowland, M.D. Dukes, S.A. Sargent, American Journal of Potato Research, 91(5), 504 (2015)

11. A.S. Ovchinnikov, A.A. Buber, Yu.P. Dobrachev, V.V. Borodychev, News of the Nizhnevolzhsky agro-university complex: science and higher professional education, 4, 65 (2018)

12. N.B. Martynova, A.Yu. Korneev, Bulletin of the Federal State Educational Institution of Higher Professional Education "Moscow State Agroengineering University named after V.P. Goryachkin", 2(84), 18 (2018) 
13. E.V. Zhalnin, Bulletin of the Federal State Educational Institution of Higher Professional Education "Moscow State Agroengineering University named after V. P. Goryachkin", 6(82), 10 (2017)

14. N.K.Telovov, Kh.A. Abdulmazhidov, The Herald of the Moscow State Agricultural Engineering University named after V.P. Goryachkin, 91(3), 22 (2019)

15. O.A. Starovoitova, N.E. Shabanov, Bulletin of the Federal State Educational Institution of Higher Professional Education "Moscow State Agroengineering University named after V. P. Goryachkin", 4, 34 (2016)

16. A.S. Shtanko, V.N.Shkura, Scientific journal of the Russian Research Institute of Melioration Problems, 3(31), 39 (2018)

17. N.B. Martynova, G.I. Bondareva, S.K. Toygambaev, N.K. Telovov, Journal of Physics: Conference Series. Krasnoyarsk Science and Technology City Hall of the Russian Union of Scientific and Engineering Associations. Krasnoyarsk, Russian Federation, 42091 (2020)

18. L.V. Kireycheva, V.M.Yanshin, Melioration and water management, 5, 31 (2019)

19. N.B. Martynova, S.K. Toygambaev, N.K. Telovov, K. Shavasov, Sh. Yusupov, 1st International Conference on Energetics, Civil and Agricultural Engineering. Tashkent, Usbekistan (2020)

20. V.P., Maksimenko, V.A. Shevchenko, V.K. Gubin, Bulletin of the International academy of Agricultural Education, 36, 82 (2017) 